\title{
Stem Cell Mechanobiology
}

\author{
David A. Lee," Martin M. Knight, Jonathan J. Campbell, and Dan L. Bader \\ School of Engineering and Materials Science, Queen Mary, University of London, Mile End Road, London E1 4NS, UK
}

\begin{abstract}
Stem cells are undifferentiated cells that are capable of proliferation, self-maintenance and differentiation towards specific cell phenotypes. These processes are controlled by a variety of cues including physicochemical factors associated with the specific mechanical environment in which the cells reside. The control of stem cell biology through mechanical factors remains poorly understood and is the focus of the developing field of mechanobiology. This review provides an insight into the current knowledge of the role of mechanical forces in the induction of differentiation of stem cells. While the details associated with individual studies are complex and typically associated with the stem cell type studied and model system adopted, certain key themes emerge. First, the differentiation process affects the mechanical properties of the cells and of specific subcellular components. Secondly, that stem cells are able to detect and respond to alterations in the stiffness of their surrounding microenvironment via induction of lineage-specific differentiation. Finally, the application of external mechanical forces to stem cells, transduced through a variety of mechanisms, can initiate and drive differentiation processes. The coalescence of these three key concepts permit the introduction of a new theory for the maintenance of stem cells and alternatively their differentiation via the concept of a stem cell 'mechano-niche', defined as a specific combination of cell mechanical properties, extracellular matrix stiffness and external mechanical cues conducive to the maintenance of the stem cell population. J. Cell. Biochem. 112: 1-9, 2011. ㅇ 2010 Wiley-Liss, Inc.
\end{abstract}

KEY WORDS: EMBRYONIC STEM CELL; MESENCHYMAL STEM CELL; MECHANOBIOLOGY; CELL MECHANICS; DIFFERENTIATION; EXTRACELLULAR MATRIX

\section{STEM CELLS AND MECHANOBIOLOGY}

Stem cells are undifferentiated cells that are capable of proliferation, self-maintenance and differentiation towards specific cell phenotypes [Morrison et al., 1997; Reya et al., 2001]. The possession of these features make stems cells an attractive source for cell-based regenerative therapies. However, the success of such therapies is dependent on the understanding, and ultimately the control of the processes of both self-maintenance, required to maintain their 'stem-ness' and also lineage-specific differentiation. Self-maintenance and differentiation of stem cells in vivo are controlled by a microenvironment described as the 'stem cell niche', which has been defined as a specific location in a tissue where stem cells reside for an indefinite period of time and produce progeny cells while self-renewing [Ohlstein et al., 2004]. Cells that are no longer retained within the niche environment may undergo differentiation, that is also controlled by factors associated with their new microenvironment. The microenvironmental cues are diverse and complex in nature, but typically involve soluble and insoluble macromolecular factors, but also physicochemical factors associated with the specific mechanical environment in which the cells reside. While the role of macromolecular factors and their intracellular signalling pathways have received extensive study, the control of stem cell biology through mechanical factors remains poorly understood and is the focus of the developing field of mechanobiology.

Mechanobiology is defined as the study of mechanisms by which cells detect and respond to mechanical stimuli. The mechanical forces imposed on the growing and differentiating foetal tissues play an increasingly critical role in the developmental process, effectively guiding the development of the functional organism. Post-partum, mechanical demands increase dramatically. As such major morphological changes progressively unfold under the influence of the mechanical stimuli provided by external gravitational forces and muscular contraction. Indeed mechanical forces have been reported to affect developmental processes as diverse as gastrulation in Drosophili [Desprat et al., 2008], left/right reversal of major organs in vertebrates associated with abnormal fluid flow [Kartagener and Stucki, 1962], cardiogenesis [Patwari and Lee, 2008] and skeletogenesis. Three major contributory factors may be involved. First direct cell-generated forces, associated with the

Grant sponsor: EPSRC Platform Grant; Grant number: EP/E046975/1; Grant sponsor: Human Frontier Science Progam; Grant number: RGP0025/2009-C.

*Correspondence to: Prof. David A. Lee, School of Engineering and Materials Science, Queen Mary, University of London, Mile End Road, London, E1 4NS, UK. E-mail: d.a.lee@qmul.ac.uk

Received 21 June 2010; Accepted 22 June 2010 •DOI 10.1002/jcb.22758 • C 2010 Wiley-Liss, Inc.

Published online 12 July 2010 in Wiley Online Library (wileyonlinelibrary.com). 
contractile components of the cytoskeleton and associated linkages to the extracellular matrix. Secondly, the ability of cells to detect and respond to the stiffness of their surrounding environment, via durotaxis and finally, the effect of external mechanical forces, generated via gravitational effects, muscle action or other cell contractile processes. These processes do not work in isolation and the mechanical environment of stem cells may involve contributions from all three processes in a highly complex and interacting manner.

Mechanobiology contributes first to the understanding of the hierarchical mechanical properties at the tissue, cellular and subcellular levels and the inter-relationship between these properties. Moreover, mechanobiology reveals fundamental processes associated with development, normal physiology and pathology, through elucidation of mechanotransduction pathways, by which mechanical perturbation is transduced into a biological response. Furthermore, it is fundamental to tissue cell-based regenerative strategies, particularly for load-bearing tissues. This has led to the development of ex vivo bioreactors that incorporate mechanical conditioning and advanced scaffold designs that provide a controlled micromechanical environment, thereby permitting the manipulation of fundamental mechanotransduction pathways. These approaches have been applied to both differentiated cells and stem cells. With reference to the latter, mesenchymal stem cells (MSCs) have been most extensively studied, due to their role in the formation and maintenance of load-bearing tissues of the musculoskeletal system. This review will outline both theoretical and experimental approaches designed to explore the role of a variety of mechanical stimuli in controlling stem cell maintenance and differentiation.

\section{THE STEM CELL MECHANICAL ENVIRONMENT AND THEORETICAL MODELS OF STEM CELL DIFFERENTIATION}

The mechanical environment within tissues is complex, often involving combinations of fluid pressurisation, tensile or compressive deformation and associated fluid flow-induced shear forces. The situation is further complicated within developing tissues, as the differentiation process itself results in alterations of the mechanical properties of both extracellular matrix and the resident cells. As such there is a temporal modulation of the mechanical environment of stem cells that unfolds in conjunction with cell differentiation and tissue morphogenesis. A number of researchers have proposed that the processes of mechanical modulation and tissue differentiation are intrinsically linked, with the mechanical environment driving differentiation. This hypothesis has been investigated through a variety of experimental and theoretical studies.

For example, the amorphous mass of undifferentiated mesenchymal cells, responsible for the development of the skeleton, is susceptible to the influence of mechanical signals mediated through the extracellular matrix [Carter and Beaupré, 2001]. It has long been postulated that adventitious, secondary cartilage develops on cranial membrane bones of the embryo in response to intermittent pressure and tension, associated with movement [Hall, 1972]. The importance of intermittent loading to chondrogenic development has been further supported by studies involving joint immobilisation in the developing chick embryo [Murray and Drachman, 1969; Hall, 1972]. Indeed following paralysis of skeletal muscles, abnormalities were reported to develop, including the absence of synovial joint cavities, the fusion of long bones by fibrous tissue cartilage or bone, the absence of adventitious and articular cartilages and the distortion of the skeleton [Murray and Drachman, 1969].

An alternative approach has involved the use of theoretical models to predict the effects of a variety of mechanical stimuli on lineage-specific stem cell differentiation. These models have been used to predict tissue differentiation during skeletogenesis, fracture healing, bone distraction and the development of pseudoarthroses [Carter and Beaupré, 2001]. As early as 1960, Pauwels proposed that tissue deformation or stretching induces the formation of fibrous connective tissue while compression induces cartilage formation [Pauwels, 1960] (Fig. 1A). More recently researchers have made use of finite element analysis, a common technique in engineering to estimate the internal mechanical state within structures, to predict the influence of hydrostatic pressure and distortional strain on tissue differentiation [Blenman et al., 1989; Carter et al., 1998]. These models suggest a correlation between high levels of compressive hydrostatic stress and chondrogenesis; low hydrostatic stress and osteogenesis; and high distortional strain associated with the formation of fibrous connective tissue or fibro-cartilage, as indicated in Figure 1B.

Further adaptations of the modelling approach enable the establishment of critical values for mechanical parameters in relation to differentiation. For example, a study proposed that local strains lower than 5\% induce intramembranous ossification, while hydrostatic pressures greater than $0.15 \mathrm{MPa}$ and local strains smaller than 15\% induce endochondral ossification [Claes and Heigele, 1999]. However, from a biological viewpoint, it is clearly naïve to suggest that in all conditions these critical values represent sharply delineated 'cut-off' values that will predict the differentiation of tissues under the influence of distortional strain and hydrostatic stress. Indeed fundamental changes occur within differentiating tissues which can drastically change the nature of loading, for example, the generation of extracellular matrix [Prendergast et al., 1997]. In an attempt to analyse mesenchymal cell differentiation, finite element models were developed, which incorporate the effects of the relative velocity of fluid and solid constituents, fluid pressure and tissue deformation [Prendergast et al., 1997]. The synthesis of extracellular matrix by differentiating MSCs may, or may not, favour the mechanical and perfusion characteristics required for lineagespecific differentiation within that tissue, driving the progression of cell phenotype in a step-wise manner. A 'mechano-regulatory' pathway (Fig. 1C) describes mesenchymal differentiation in a temporal manner, where the emergence of a specific extracellular matrix (Point $\mathrm{X}$-Fig. 1C) can favour a divergence in phenotype (red dashed line) from a steady-state condition (solid line). In the presence of significant shear strain and associated motion, fluid velocity and shear forces are also maintained favouring differentiation to fibrous connective tissue. However, an up-regulation or change in collagenous matrix production leads to a higher stiffness and consequent reduction in fluid velocity and shear force leading to osteogenic differentiation. 


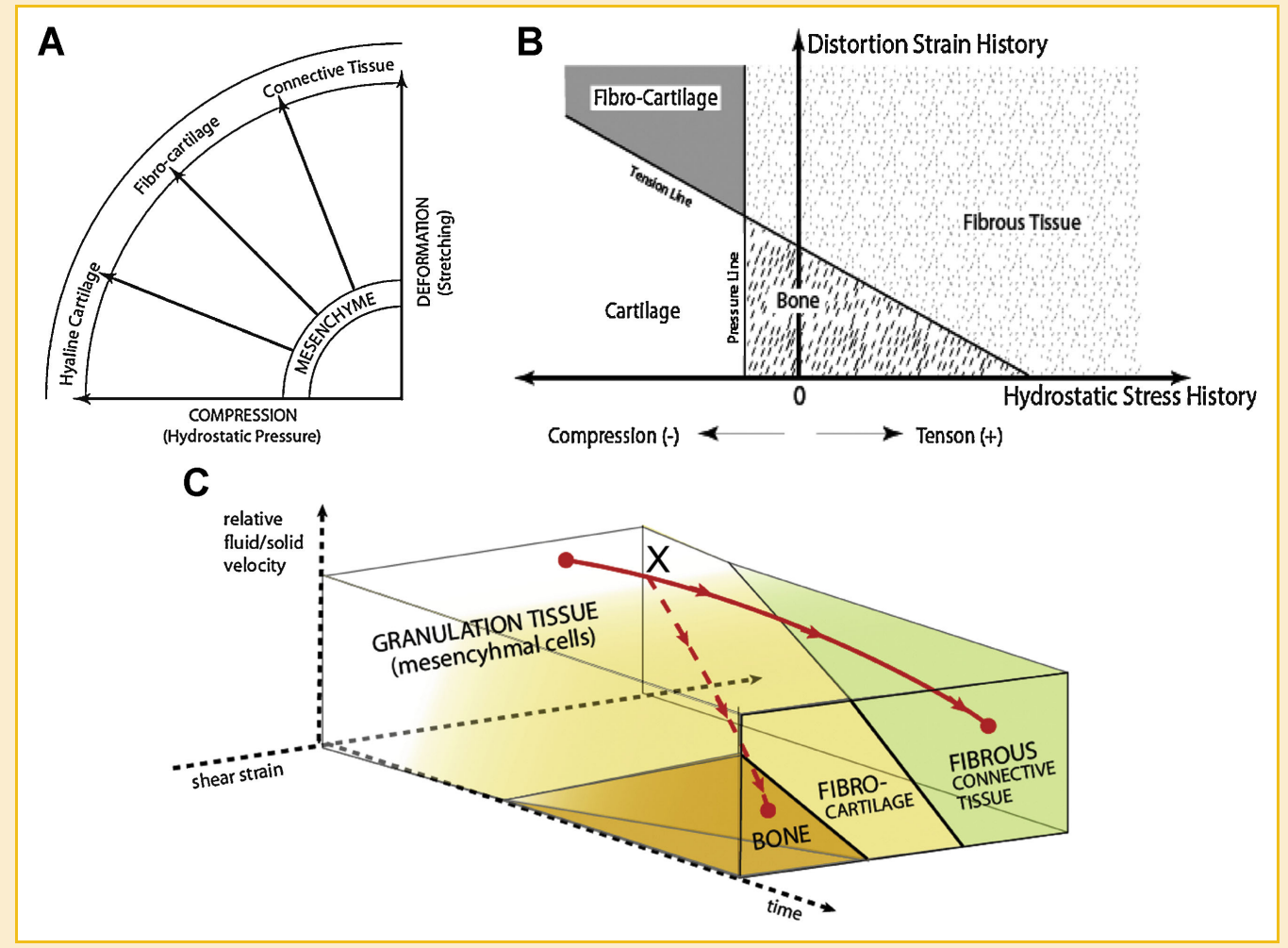

Fig. 1. Theoretical models developed by (A) Pauwels [1960], (B) Carter and Beaupré [2001] and (C) Prendergast et al. [1997] that describe the relationship between the mechanical environment and mesenchymal tissue differentiation. [Color figure can be viewed in the online issue, which is available at wileyonlinelibrary.com.]

More recent developments on the modelling approach have incorporated other parameters that may interact with the mechanical stimuli to direct differentiation, most notably alterations in the oxygen environment and associated angiogenesis [Checa and Prendergast, 2009]. This model also incorporates cell migration, proliferation and apoptosis and has been further developed to incorporate physiological variation in cellular parameters to predict animal to animal variation in differentiation reported in vivo within a defined bone chamber model subjected to mechanical loading [Khayyeri et al., 2009].

\section{STEM CELL MECHANICS AND IN VITRO MODEL SYSTEMS}

The mechanical properties of stem cells influence their response to the mechanical environment, their ability to migrate and ultimately their differentiation. Consequently, in vitro model systems have been developed to examine cellular and intracellular mechanics of stem cells, the influence of external mechanical forces on differentiation and the associated mechanotransduction signalling pathways. These techniques allow investigation of the hypotheses that arise from the theoretical modelling studies described above. The ideal approach involves simulating the in vivo mechanical environment within a defined in vitro model system. Those studies attempting to characterise the mechanical properties of stem cells and their intracellular components, tend to utilise a short-term loading approach, often coupled with live cell microscopy techniques.
Many of these studies involve the application of a mechanical force to an individual cell. However, to investigate the influence of mechanical forces on stem cell metabolism and differentiation, separate model systems are required involving prolonged culture in the presence of mechanical perturbation. These studies often employ a population of cells cultured either in monolayer or within a 3D scaffold. This enables the examination of the heterogeneity of any response, due to the possible presence of subpopulations of cells and also spatial differences in the mechanical environment, such as localised differences in strain or fluid flow. Both single cell and population approaches may be used to examine the underlying mechanotransduction signalling behaviour in stem cells.

A description of the key common model systems used and their contribution to stem cell mechanobiology is outlined in the following sections. These may be divided into systems used for short-term mechanical loading of single cells (Fig. 2) and systems for longer-term loading of entire cell populations (Fig. 3).

\section{STEM CELL MECHANICS-SINGLE CELL APPROACHES}

\section{MICROPIPETTE ASPIRATION}

The micropipette aspiration technique is used to deform an individual cell with a known aspiration pressure (see Fig. 2a). Such a technique has been widely used to determine the mechanical properties of a variety of cell types including stem cells [Hochmuth, 2000]. Micropipettes, with inner diameters typically between 5 and 


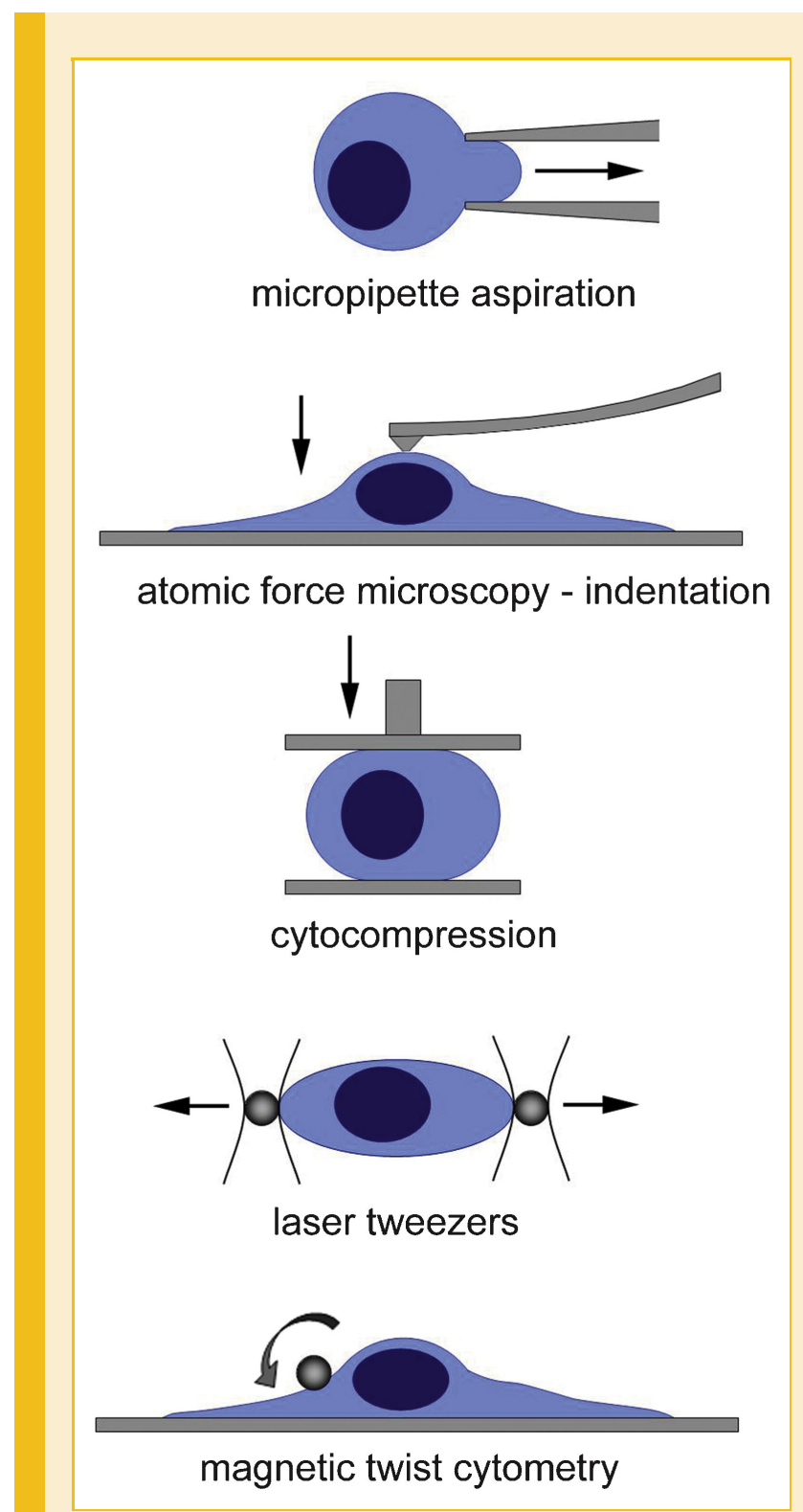

Fig. 2. Schematic representation of experimental techniques used to investigate the mechanical properties of individual stem cells. [Color figure can be viewed in the online issue, which is available at wileyonlinelibrary.com.]

$15 \mu \mathrm{m}$, may be used to induce deformation of the whole cell, or alternatively discrete regions of the cell, depending on the cell diameter. Moreover, the properties of subcellular components, most notably the nucleus and cytoskeleton may be investigated. With the control of a hydraulic micromanipulator, the micropipette is moved into contact with the cell surface and pressures applied and the cell visualised using bright field or fluorescence microscopy. Two approaches have been used for performing the aspiration technique.

For the incremental approach, pressure is applied typically in steps up to $5 \mathrm{cmH}_{2} \mathrm{O}(0.49 \mathrm{kPa})$, with the equilibrium cell aspiration length, $\mathrm{L}$, recorded at each pressure. The apparent Young's modulus may then be determined using a theoretical model [Theret et al., 1988]. In this model, the cell is assumed to be a homogeneous, elastic half-space material and the Young's modulus, E, is therefore given as follows, where $\Phi(\eta)$ is defined as the wall function with a typical value of 2.1 :

$$
\mathrm{E}=\frac{3 \phi(\eta)}{2 \pi}\left(\frac{\Delta \mathrm{P}}{\mathrm{L} / \mathrm{a}}\right)
$$

The Young's modulus can thus be determined from the slope of the linear regression of the normalised length L/a versus the negative suction pressure $P$.

For the alternative approach, in which pressure is applied in a single step, the following equation is fitted to the temporal changes in aspiration length measured experimentally (Eq. 2). This model assumes that the cell behaves as a homogenous linear viscoelastic three-parameter solid half-space.

$$
\mathrm{L}(\mathrm{t})=\frac{\phi(\eta) \mathrm{a} \Delta \mathrm{P}}{\pi \mathrm{k}_{1}}\left(1-\frac{\mathrm{k}_{2}}{\mathrm{k}_{1}+\mathrm{k}_{2}} \mathrm{e}^{-\mathrm{t} / \tau}\right)
$$

The pipette internal diameter is given by ' $a$ ' whilst the relaxation time constant ' $\tau$ ' is defined as follows (Eq. 3).

$$
\tau=\frac{\mu\left(\mathrm{k}_{1}+\mathrm{k}_{2}\right)}{\mathrm{k}_{1} \mathrm{k}_{2}}
$$

The parameter $\mathrm{k}_{1}$, is termed the equilibrium or relaxation modulus $\left(\mathrm{E}_{\mathrm{r}}\right.$ or $\left.\mathrm{E}_{\infty}\right), \mathrm{k}_{1}+\mathrm{k}_{2}$ is the instantaneous modulus $\left(\mathrm{E}_{\mathrm{i}}\right)$ and $\mu$ is the apparent viscosity. Using this viscoelastic model it is also possible to determine the apparent equilibrium Young's model given by:

$$
\mathrm{E}=\left(\frac{3}{2}\right) \mathrm{k}_{1}
$$

It should be recognised that although these models benefit from being simple, they neglect geometrical factors, such as finite cell dimensions, evolution of cell-micropipette contact region and curvature of the micropipette edges. Thus, other models incorporating these geometric factors into a computational form have been developed [Haider and Guilak, 2000], which can also account for the inhomogeneities in the cellular properties.

In a recent study, the mechanical properties of MSCs were assessed using micropipette aspiration in their undifferentiated state and during osteogenic and adipogenic differentiation [Yu et al., 2010]. The authors report values for instantaneous and equilibrium Young's moduli for the undifferentiated cells of approximately 450 and $100 \mathrm{~Pa}$, respectively. These values rise significantly and progressively during osteogenic differentiation over a 21-day period to reach values approximately twice that of the undifferentiated cells. These changes are closely associated with alterations in the cell size and morphology, and with alterations in the cytoskeleton. Indeed a previous study demonstrated a significant reduction in the modulus of MSCs following disruption of the actin cytoskeletal organisation [Tan et al., 2008]. Embryonic stem cells have also been studied using micropipette aspiration, with results suggesting a marked stiffening of the nucleus during differentiation, associated with the nuclear skeletal component Lamin A/C, which is only expressed in differentiating cells [Pajerowski et al., 2007]. These findings suggest that both embryonic stem cells and MSCs may be more deformable than their differentiated progeny. This 


\section{Mode of cell strain}
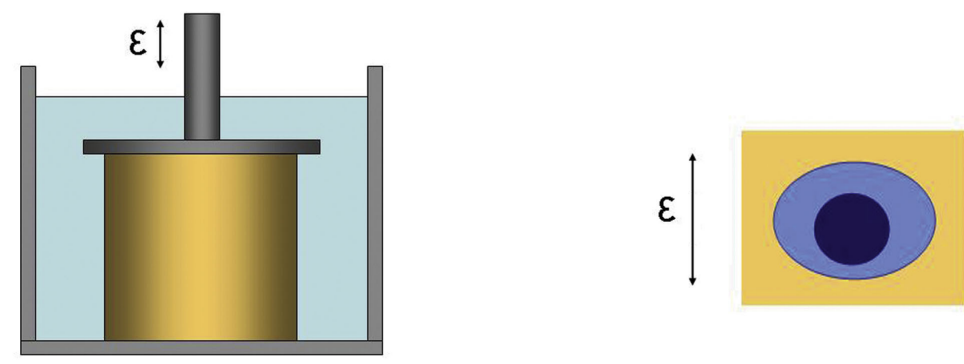

compression applied to cells in 3D scaffold
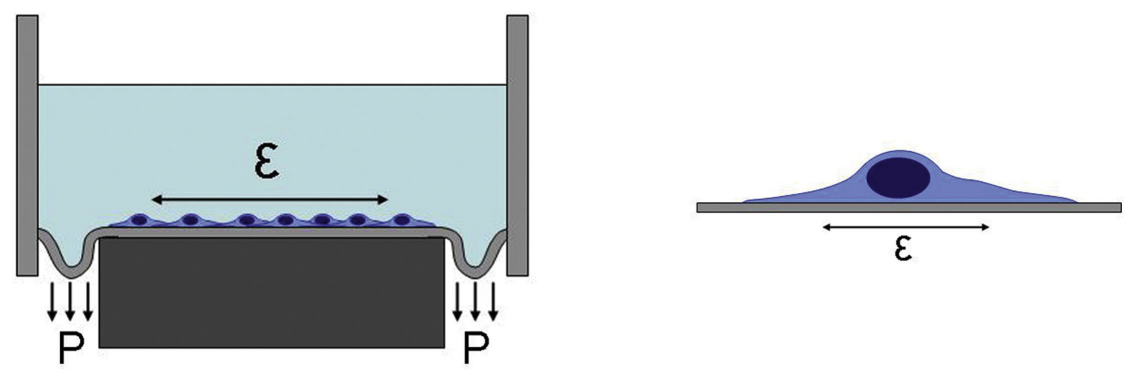

substrate tension applied to cells in monolayer
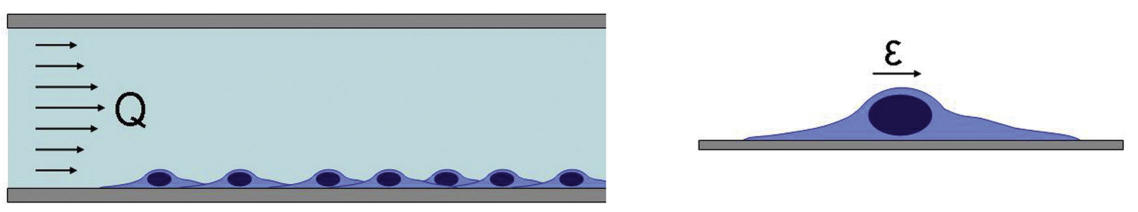

fluid shear applied to cells in monolayer culture

Fig. 3. Schematic representation of experimental systems used to apply compressive, tensile or fluid flow induced shear strain ( $\varepsilon$ ) to populations of stem cells in vitro. [Color figure can be viewed in the online issue, which is available at wileyonlinelibrary.com.]

physical plasticity may facilitate the migration of stem cells through solid tissues to the sites of tissue damage.

\section{ATOMIC FORCE MICROSCOPY (AFM) AND CYTOINDENTATION}

AFM and related cytoindentation/compression techniques have also been used to investigate stem cell mechanics through the application of a defined deformation to a cell, or a region of a cell. The technique involves the indentation of the cell surface with a small probe, whose movement is controlled at constant velocity and can be imaged through a conventional light microscope [Radmacher et al., 1996; Sato et al., 2000]. The tip or probe can interact with various locations on the cell surface with the force indirectly recorded under indentation control of the tip. Hence structural properties, in the form of the force-deformation relationship, can be obtained. However, in order to extract material properties such as cell modulus, from a stress-strain response, finite element models have been proposed to account for the shape of the probe tip and, potentially, its small size relative to the depth of indentation [Costa and Yin, 1999]. These techniques have been applied to characterise the mechanical properties of a number of cells, with comparisons made between undifferentiated and differentiated cells. For example, single indentation studies on undifferentiated and early differentiating mouse embryonic stem cells revealed that the mechanical properties of the undifferentiated cell was different from day 6 differentiating cells [Pillarisetti et al., 2009]. In a similar manner human embryonic stem cells exhibit a progressive increase in modulus as the cells differentiate toward a chondrogenic phenotype [Ofek et al., 2009]. Differences have also been reported in the mechanical properties of MSCs, derived from either bone marrow or adipose tissue and cells from their relevant differentiated lineages, namely osteoblasts, chondrocytes and adipocytes [Darling et al., 2007]. The authors report similar properties for both stem cell types. However, there were notable differences between the stem and differentiation cells in terms of the ratio between elastic and viscoelastic, or time-dependent. Specifically, the stems cells exhibited higher ratio values, suggesting that the cells are initially 
very stiff but would not resist sustained loading over time. It has also been suggested that alterations in mechanical properties during MSC differentiation may be associated with the cytoskeletal organisation [Yourek et al., 2007].

\section{MECHANICALLY INDUCED STEM CELL DIFFERENTIATION - CELL POPULATION APPROACHES}

\section{APPLICATION OF SUBSTRATE TENSION TO STEM CELLS CULTURED ON NON-RIGID SUBSTRATES}

It is possible to culture a wide variety of cell types, including many stem cell types, as an adherent monolayer on a 2D substrate without disruption of the cellular phenotype. These studies traditionally use rigid substrates, such as tissue culture plastic, but the utilisation of non-rigid substrates permits study of various aspects of mechanobiology. First the deformation of the substrate under the action of cell-generated force, permits assessment of the intrinsic contractile characteristics of the cells. Moreover, the use of substrates with a variety of stiffness permits interrogation of the ability of cells to detect and respond to their extracellular mechanical environment. These latter studies have been instrumental in determining the role of durotactic mechanisms in driving stem cell differentiation. In a seminal study, it was demonstrated that MSCs adapt to the stiffness of their substrate by differentiating toward lineages that reflect the substrate stiffness [Engler et al., 2006]. Thus, cells grown on soft substrates, with a stiffness equivalent to that of brain tissue, differentiated into neurons. By contrast cells grown on a substrates with similar stiffness to muscle or bone appropriately differentiated into myocytes or osteoblasts. A similar effect has recently been reported for embryonic stem cells, with substrate stiffness affecting genes, such as Brachyury, Mixl-1 and Eomes, that are expressed during gastrulation and are associated with mesodermal and endodermal differentiation [Evans et al., 2009]. Stiffer substrates also preferentially differentiate neural stem/progenitor cells to oligodendrocytes, rather than astrocytes [Leipzig and Shoichet, 2009]. The effects appear, mechanistically, to be associated with both differential spreading and the interactions between the cytoskeleton and the extracellular matrix.

Other studies have superimposed a range of tensile mechanical stimuli on cells cultured on a deformable substrate. By far the most common approach is to culture cells on an elastomeric membrane, which may be coated with a variety of adhesion molecules, such as collagen 1, fibronectin or laminin. Using this approach a number of variables can be studied, including orientation of strain (uniaxial vs. biaxial), the magnitude, frequency and duration of dynamic tensile strain regimes and the nature of the modified substrate surface. A number of recent studies have reported enhancement of osteogenic differentiation by MSCs on application of cyclic tensile strain, typically at magnitudes ranging from $0.4 \%$ to 5\% [Ward et al., 2007; Chen et al., 2008; Huang et al., 2009]. Higher levels of tensile strain favour differentiation toward a tendon/ligament-type phenotype or myogenic differentiation [Chen et al., 2008]. These findings concur with predictions arising from the theoretical models described above.

\section{APPLICATION OF FLUID SHEAR TO STEM CELLS}

The application of fluid flow results in the generation of a shear stress at the cell-fluid interface (Fig. 3). The influence of fluid shear stress has been most widely examined in relation to differentiated vascular endothelial cells and osteoblasts/cytes, however, several recent studies have investigated the effects of fluid shear on the differentiation of stem cells. Both cone-and-plate and parallel plate flow chambers have been employed in conjunction with cells cultured in monolayer [Sato et al., 1996; Deguchi et al., 2005]. In contrast to substrate tension, where the greatest cell strain occurs along the basal surface, fluid shear generates greatest cell distortion on the apical surface. However, even at low very low shear stress there may be distortion of transmembrane cellular components such as the primary cilium or the glycocalx. The nature of the flow environment may influence response, with the magnitude of the shear stress being determinative of cellular response. Moreover, differences between continuous flow and dynamic flow environments involving pulsatile or oscillatory flow regimes have been reported.

The initiation and maintenance of embryoid bodies from mouse embryonic stem cells is sensitive to alterations in the hydrodynamic environment, induced via rotary orbital suspension culture [Sargent et al., 2009]. Moreover, profound differences in the gene expression profile were demonstrated at various rotary orbital speeds. Shear stress is also reported to influence the endothelial differentiation by embryonic stem cells, demonstrated by increased expression of the vascular endothelial cell-specific markers Flk-1, Flt-1, vascular endothelial cadherin, and PECAM-1 [Yamamoto et al., 2005]. Similar effects have been reported for the induction of haematopoiesis from mouse embryonic stem cells [Adamo et al., 2009].

The exposure of MSCs to shear stress induces increased proliferation and modulation of signaling pathways including intracellular calcium signaling and activation of ERK 1 and 2, indicating the involvement of the MAPK pathways [Li et al., 2004; Riddle et al., 2006]. The exposure to low magnitudes of shear stress (0.3-2.7 dyn $/ \mathrm{cm}^{2}$ ) induce osteogenic differentiation, including increased expression of osteopontin and osteocalcin [Li et al., 2004; Kreke et al., 2005, 2008]. Other studies have suggested that higher magnitudes of shear stress may induce the expression of endothelial cell markers, such as CD31, von Willebrand factor, and vascular endothelial-cadherin, from a mesenchymal progenitor cell line [Wang et al., 2005].

\section{APPLICATION OF MECHANICAL STIMULATION TO STEM CELLS SEEDED IN 3D SCAFFOLDS}

For many cell types, including stem cells, model systems have been developed that involve culturing the cells within a 3D scaffold. These systems may be used for mechanobiology studies, with tensile or compressive strain applied to the scaffold transferred through the scaffold material to the seeded cells (Fig. 3). Accordingly, studies have examined the response of stem cells subjected to mechanical stimuli within a wide variety of 3D scaffold systems. For low modulus scaffolds, such as the widely used hydrogels, agarose and alginate, compressive strain can be applied using relatively simple bioreactor systems and monitored using microscope-mounted loading rigs, to enable simultaneous visualisation of cells at diffe- 
rent levels of applied gross compression. The mechanical environment associated with macroporous or fibrous scaffolds is more complex than simple hydrogel systems due to the wide variation in cell attachment geometries.

Much of the work in this context has focussed on musculoskeletal differentiation by MSCs, in effect providing experimental validation of the theoretical models described above. Chondrogenesis has been demonstrated to be enhanced by dynamic compression in studies conducted by a number of groups involving scaffolds including agarose, alginate and fibrin-polyurethane composites [Angele et al., 2004; Campbell et al., 2006; Mouw et al., 2007; Li et al., 2010]. These studies have typically identified alterations in cartilage-specific gene expression including SOX-9, collagens II \& X and aggrecan. Compression has also been demonstrated to influence intracellular calcium signalling in MSCs within alginate constructs [Campbell et al., 2008]. Most of these studies have considered a single loading regime, however a recent study by $\mathrm{Li}$ et al. [2010] investigated a range of regimes that may, theoretically, drive differentiation of adult MSCs toward chondrogenic, osteogenic or fibrous lineages. They demonstrated that higher dynamic frequencies and higher compression amplitudes induced the greatest chondrogenic gene expression, while lower amplitude/lower frequency conditions induced a greater ratio of osteogenic markers (osterix, collagen I) to chondrogenic markers.

Similar studies have been performed using embryonic progenitor and stem cells. Takahashi et al. [1998] studied the effects of static compression on murine embryonic limb bud cells encapsulated in a collagen gel system. Statically compressed samples showed enhanced appearance of toluidine blue stained cartilage nodules and collagen type $\mathrm{X}$ staining compared to free-swelling controls. An accelerated process of chondrogenesis under static compression was observed by gene expression analysis for collagen type II and aggrecan. Indeed, type-II collagen expression was directly proportional to the magnitude of the applied force. Other studies have also examined the effects of dynamic compressive stress on chondrogenesis in vitro [Elder et al., 2001]. Limb-bud cells, seeded in 3\% agarose constructs and exposed to dynamic loading $(0.25-9.0 \mathrm{kPa}$ at $0.33 \mathrm{~Hz}$ ), exhibited an increase in cartilage nodule formation compared to unloaded and statically loaded controls. Dynamic loading increased the amount of sulphate incorporation twofold when compared to control constructs.

\section{CONCLUSIONS}

The preceding sections provide an insight into the current knowledge of the role of mechanical forces in the induction of differentiation of stem cells. While the details associated with individual studies are complex and typically associated with the stem cell type studied and model system adopted, certain key themes emerge. First, the differentiation process affects the mechanical properties of the cells and of specific subcellular components such as the nucleus. Secondly, that stem cells are able to detect and respond to alterations in the stiffness of their surrounding microenvironment via induction of lineage-specific differentiation. Finally, the application of external mechanical forces to stem cells, transduced

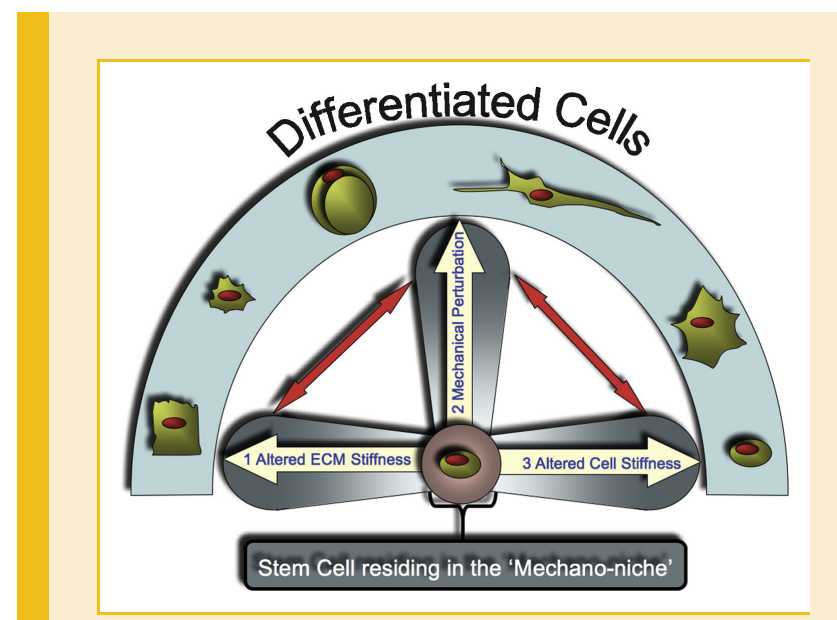

Fig. 4. The stem cell mechano-niche concept. [Color figure can be viewed in the online issue, which is available at wileyonlinelibrary.com.]

through a variety of mechanisms, can initiate and drive differentiation processes.

The coalescence of these three key concepts permit the introduction of a new theory for the maintenance of stem cells and alternatively their differentiation via the concept of a stem cell 'mechano-niche', as illustrated schematically in Figure 4. The mechano-niche may be defined as a specific combination of cell mechanical properties, extracellular matrix stiffness and external mechanical cues conducive to the maintenance of the stem cell population. Accordingly, alterations in any of these parameters may cause the stem cell no longer to be retained with the mechano-niche and to undergo differentiation under the control of its new microenvironment. The initial trigger for loss of mechano-niche environmental conditions may come from any of the three factors. For example, alteration in the mechanical properties of the neighbouring extracellular matrix (Fig. 4-labelled 1) as a result of local matrix formation may drive differentiation through mechanisms associated with substrate stiffness. Alternatively, the introduction of external or cell-generated mechanical perturbation (Fig. 4-labelled 2), induces loss of mechano-niche properties that results in subsequent alterations in cell (Fig. 4-labelled 3) and matrix stiffness as the stem cell begins to differentiate. Finally, induction of differentiation via non-mechanical mechanism, for example, associated with the presence of growth factors or altered oxygen levels will rapidly cause loss of mechano-niche conditions as the cell and matrix stiffness alter. Moreover, the inter-relationship between the three major controlling factors (red arrows) suggest that alteration to one factor will subsequently lead to alterations to the other two factors, thereby reinforcing the drive to differentiation once a cell has left its mechano-niche. The reinforcement of differentiation cues supports the directionality of the differentiation process, wherein cells are unlikely to be able to regain the factors necessary for the mechano-niche once they have been lost. Thus, under normal physiological conditions differentiation is a directional process. However, it would be interesting to determine whether reprogramming of differentiated cells to a stem cell like phenotype, for example, associated with the derivation of induced 
pluripotent stem cells from fibroblasts is associated the recreation of mechano-niche environmental conditions.

In conclusion, this review suggests that the mechanical environment plays an important role in controlling both the maintenance of stem cells and their lineage-specific differentiation. Currently, our understanding of the mechanisms underpinning these processes remain limited and further research in the field of mechanobiology will be pivotal to our developing understanding of stem cell biology.

\section{REFERENCES}

Adamo L, Naveiras 0, Wenzel PL, McKinney-Freeman S, Mack PJ, GraciaSancho J, Suchy-Dicey A, Yoshimoto M, Lensch MW, Yoder MC, GarcíaCardeña G, Daley GQ. 2009. Biomechanical forces promote embryonic haematopoiesis. Nature 459:1131-1135.

Angele P, Schumann D, Angele M, Kinner B, Englert C, Hente R, Füchtmeier B, Nerlich M, Neumann C, Kujat R. 2004. Cyclic, mechanical compression enhances chondrogenesis of mesenchymal progenitor cells in tissue engineering scaffolds. Biorheology 41:335-346.

Blenman PR, Carter DR, Beaupré GS. 1989. Role of mechanical loading in the progressive ossification of a fracture callus. J Orthop Res 7:398-407.

Campbell JJ, Lee DA, Bader DL. 2006. Dynamic compressive strain influences chondrogenic gene expression in mesenchymal stem cells. Biorheology 43:455-470.

Campbell JJ, Bader DL, Lee DA. 2008. Mechanical loading modulates intracellular calcium signalling in human mesenchymal stem cells. J Appl Biomat Biomech 6:9-15.

Carter DR, Beaupré GS. 2001. Skeletal tissue regeneration in skeletal function and form; mechanobiology of skeletal development, aging, and regeneration. Cambridge: Cambridge University Press.

Carter DR, Beaupré GS, Giori NJ, Helms JA. 1998. Mechanobiology of skeletal regeneration. Clin Orthop Relat Res 355S:S41-S55.

Checa S, Prendergast PJ. 2009. A mechanobiological model for tissue differentiation that includes angiogenesis: A lattice-based modeling approach. Ann Biomed Eng 37:129-145.

Chen YJ, Huang CH, Lee IC, Lee YT, Chen MH, Young TH. 2008. Effects of cyclic mechanical stretching on the mRNA expression of tendon/ligamentrelated and osteoblast-specific genes in human mesenchymal stem cells. Connect Tissue Res 49:7-14.

Claes LE, Heigele CA. 1999. Magnitudes of local stress and strain along bony surfaces predict the course and type of fracture healing. J Biomech 32:255266.

Costa KD, Yin FC. 1999. Analysis of indentation: implications for measuring mechanical properties with atomic force microscopy. J Biomech Eng 121: 462-471.

Darling EM, Topel M, Zauscher S, Vail TP, Guilak F. 2007. Viscoelastic properties of human mesenchymally-derived stem cells and primary osteoblasts, chondrocytes, and adipocytes. J Biomech 41:454-464.

Deguchi S, Maeda K, Ohashi T, Sato M. 2005. Flow-induced hardening of endothelial nucleus as an intracellular stress-bearing organelle. J Biomech 38:1751-1759.

Desprat N, Supatto W, Pouille PA, Beaurepaire E, Farge E. 2008. Tissue deformation modulates twist expression to determine anterior midgut differentiation in Drosophila embryos. Dev Cell 15:470-477.

Elder SH, Goldstein SA, Kimura JH, Soslowsky LJ, Spengler DM. 2001. Chondrocyte differentiation is modulated by frequency and duration of cyclic compressive loading. Ann Biomed Eng 29:476-482.

Engler A, Sen S, Sweeney HL, Discher DE. 2006. Matrix elasticity directs stem cell lineage specification. Cell 126:677-689.
Evans ND, Minelli C, Gentleman E, LaPointe V, Patankar SN, Kallivretaki M, Chen X, Roberts CJ, Stevens MM. 2009. Substrate stiffness affects early differentiation events in embryonic stem cells. Eur Cell Mater 18:1-13.

Haider MA, Guilak F. 2000. An axisymmetric boundary integral model for incompressible linear viscoelasticity: Application to the micropipette aspiration contact problem. J Biomech Eng 122:236-244.

Hall BK. 1972. Immobilization and cartilage transformation into bone in the embryonic chick. Anat Rec 173:391-403.

Hochmuth RM. 2000. Micropipette aspiration of living cells. J Biomech 33:15-22.

Huang $\mathrm{CH}$, Chen MH, Young TH, Jeng JH, Chen YJ. 2009. Interactive effects of mechanical stretching and extracellular matrix proteins on initiating osteogenic differentiation of human mesenchymal stem cells. J Cell Biochem 108:1263-1273.

Kartagener M, Stucki P. 1962. Bronchiectasis with situs inversus. Arch Pediatr 79:193-207.

Khayyeri H, Checa S, Tagil M, Prendergast PJ. 2009. Corroboration of mechanobiological simulations of tissue differentiation in an in vivo bone chamber using a lattice-modeling approach. J Orthop Res 27:16591666.

Kreke MR, Huckle WR, Goldstein AS. 2005. Fluid flow stimulates expression of osteopontin and bone sialoprotein by bone marrow stromal cells in a temporally dependent manner. Bone 36:1047-1055.

Kreke MR, Sharp LA, Lee YW, Goldstein AS. 2008. Effect of intermittent shear stress on mechanotransductive signaling and osteoblastic differentiation of bone marrow stromal cells. Tissue Eng Part A 14:529-537.

Leipzig ND, Shoichet MS. 2009. The effect of substrate stiffness on adult neural stem cell behavior. Biomaterials 30:6867-6878.

Li YJ, Batra NN, You L, Meier SC, Coe IA, Yellowley CE, Jacobs CR. 2004. Oscillatory fluid flow affects human marrow stromal cell proliferation and differentiation. J Orthop Res 22:1283-1289.

Li Z, Yao SJ, Alini M, Stoddart MJ. 2010. Chondrogenesis of human bone marrow mesenchymal stem cells in fibrin-polyurethane composites is modulated by frequency and amplitude of dynamic compression and shear stress. Tissue Eng Part A 16:575-584.

Morrison SJ, Shah NM, Anderson DJ. 1997. Regulatory mechanisms in stem cell biology. Cell 88:287-298.

Mouw JK, Connelly JT, Wilson CG, Michael KE, Levenston ME. 2007. Dynamic compression regulates the expression and synthesis of chondrocyte-specific matrix molecules in bone marrow stromal cells. Stem Cells 25:655-663.

Murray PDF, Drachman DB. 1969. The role of movement in development of joints and related structures: The head and neck in chick embryo. J Embryol Exp Morphol 22:349-371.

Ofek G, Willard VP, Koay EJ, Hu JC, Lin P, Athanasiou KA. 2009. Mechanical characterization of differentiated human embryonic stem cells. J Biomech Eng 131:061011.

Ohlstein B, Kai T, Decotto E, Spradling A. 2004. The stem cell niche: Theme and variations. Curr Opin Cell Biol 16(6): 693-699.

Pajerowski JD, Dahl KN, Zhong FL, Sammak PJ, Discher DE. 2007. Physical plasticity of the nucleus in stem cell differentiation. Proc Natl Acad Sci USA 104:15619-15624.

Patwari P, Lee RT. 2008. Mechanical control of tissue morphogenesis. Circ Res 103:234-243.

Pauwels DF. 1960. A new theory concerning the influence of mechanical stimuli on the differentiation of the supporting tissues. The tenth contribution to the functional anatomy and causal morphology of the supporting structure. Z Anat Entwicki Gesch 121:478-515.

Pillarisetti A, Ladjal H, Ferreira A, Keefer C, Desai JP. 2009. Mechanical characterization of mouse embryonic stem cells. Conf Proc IEEE Eng Med Biol Soc 2009:1176-1179. 
Prendergast PJ, Huiskes R, Søballe K. 1997. Biophysical stimuli on cells during tissue differentiation at implant interfaces. J Biomech 30:539548.

Radmacher M, Fritz M, Kacher CM, Cleveland JP, Hansma PK. 1996. Measuring the viscoelastic properties of human platelets with the atomic force microscope. Biophys J 70:556-567.

Reya T, Morrison SJ, Clarke MF, Weissman IL. 2001. Stem cells, cancer, and cancer stem cells. Nature 414:105-111.

Riddle RC, Taylor AF, Genetos DC, Donahue HJ. 2006. MAP kinase and calcium signaling mediate fluid flow-induced human mesenchymal stem cell proliferation. Am J Physiol Cell Physiol 290:C776-C784.

Sargent CY, Berguig GY, Kinney MA, Hiatt LA, Carpenedo RL, Berson RE, McDevitt TC. 2009. Hydrodynamic modulation of embryonic stem cell differentiation by rotary orbital suspension culture. Biotechnol Bioeng 105: 611-626.

Sato M, Ohshima N, Nerem RM. 1996. Viscoelastic properties of cultured porcine aortic endothelial cells exposed to shear stress. J Biomech 29:461467.

Sato M, Nagayama K, Kataoka N, Sasaki M, Hane K. 2000. Local mechanical properties measured by atomic force microscopy for cultured bovine endothelial cells exposed to shear stress. J Biomech 33:127-135.

Takahashi I, Nuckolls GH, Takahashi K, Tanaka 0, Semba I, Dashner R, Shum L, Slavkin HC. 1998. Compressive force promotes sox9, type II collagen and aggrecan and inhibits IL-1beta expression resulting in chon- drogenesis in mouse embryonic limb bud mesenchymal cells. J Cell Sci 111:2067-2076.

Tan SC, Pan WX, Ma G, Cai N, Leong KW, Liao K. 2008. Viscoelastic behaviour of human mesenchymal stem cells. BMC Cell Biol 9:40.

Theret DP, Levesque MJ, Sato M, Nerem RM, Wheeler LT. 1988. The application of a homogeneous half-space model in the analysis of endothelial cell micropipette measurements. J Biomech Eng 110:190-199.

Wang H, Riha GM, Yan S, Li M, Chai H, Yang H, Yao Q, Chen C. 2005. Shear stress induces endothelial differentiation from a murine embryonic mesenchymal progenitor cell line. Arterioscler Thromb Vasc Biol 25:1817-1823.

Ward DF, Jr., Salasznyk RM, Klees RF, Backiel J, Agius P, Bennett K, Boskey A, Plopper GE. 2007. Mechanical strain enhances extracellular matrixinduced gene focusing and promotes osteogenic differentiation of human mesenchymal stem cells through an extracellular-related kinase-dependent pathway. Stem Cells Dev 16:467-480.

Yamamoto K, Sokabe T, Watabe T, Miyazono K, Yamashita JK, Obi S, Ohura N, Matsushita A, Kamiya A, Ando J. 2005. Fluid shear stress induces differentiation of Flk-1-positive embryonic stem cells into vascular endothelial cells in vitro. Am J Physiol Heart Circ Physiol 288:H1915-H1924.

Yourek G, Hussain MA, Mao JJ. 2007. Cytoskeletal changes of mesenchymal stem cells during differentiation. ASAIO J 53:219-228.

Yu H, Tay CY, Leong WS, Tan SC, Liao K, Tan LP. 2010. Mechanical behavior of human mesenchymal stem cells during adipogenic and osteogenic differentiation. Biochem Biophys Res Commun 393:150-155. 